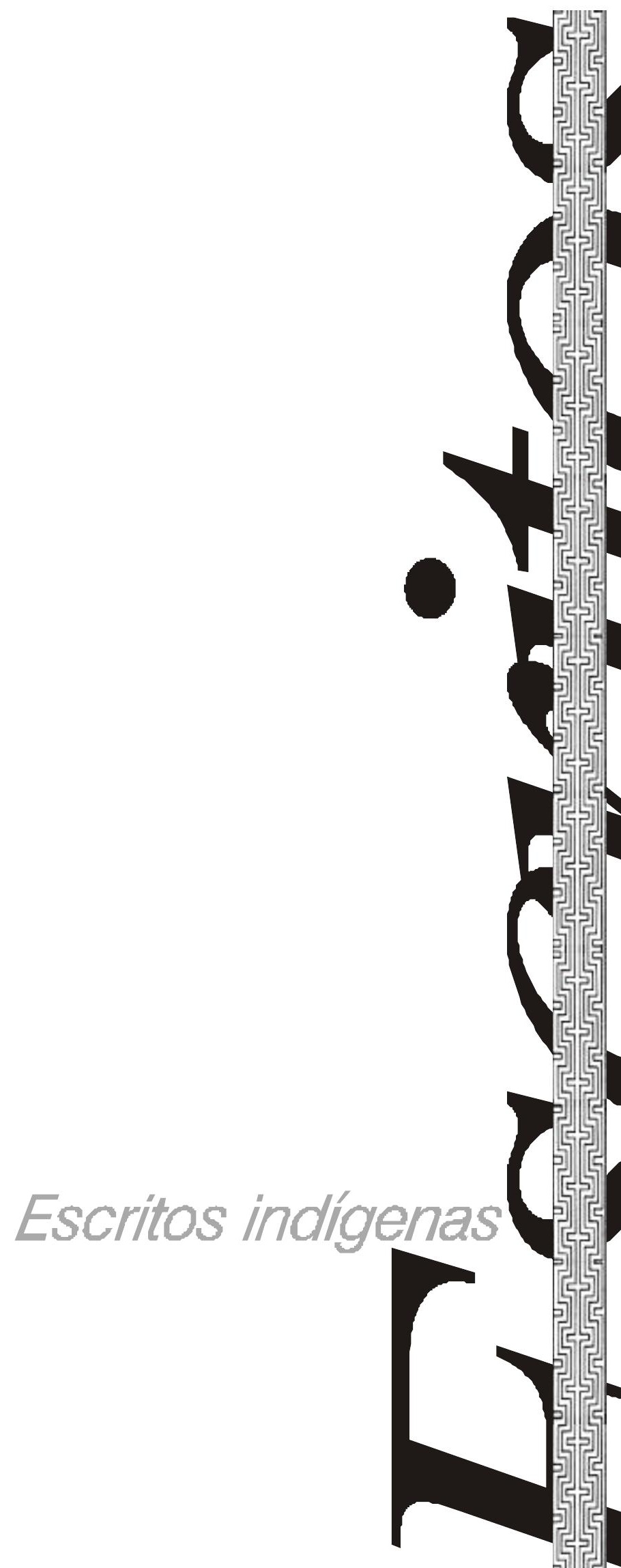





\title{
Relatos sobre o Curso de Extensão de Direito Indigenista
}

\author{
Carla Mayara Alcântara Cruz*
}

O curso de Extensão de Direito Indigenista, realizado pelo programa Rede de Saberes ${ }^{1}$ e coordenado pela Universidade Católica Dom Bosco (UCDB), teve início após uma conversa com o professor Antonio Brand, na qual eu explanei os problemas enfrentados pelos acadêmicos indígenas no curso de Direito. Durante o curso são tratadas apenas questões do Direito Positivista, o direito em si não aborda outros temas mais abrangentes. Como temos objetivos de ajudar nossas Comunidades, sempre esperamos a questão indígena ser abordada, mas muitas vezes passam por cima, nem mesmo os docentes sabem profundamente da questão indígena. Este foi um problema enfrentado por todos que cursam Direitos ou que se formaram sem saber onde estão os Direitos inerentes à questão indígena, pois a maioria dos indígenas entra na Universidade com intuito de saber para futuramente auxiliar as suas aldeias de origem com seus conhecimentos científicos.

O curso de extensão iniciou em julho de 2007, com carga horária de $150 \mathrm{~h} /$ aula, com objetivo de ajudar a todos os acadêmicos indígenas na formação do curso de Direito e unir todos os acadêmicos do Estado, para que futuramente possam atuar dentro das suas comunidades. Apóiam os órgãos colaboradores da causa indígena OAB/ $\mathrm{MS}^{2}$, NUPEJU ${ }^{3}, \mathrm{UEMS}^{4}, \mathrm{NEPPI}^{5}$ e $\mathrm{CIMI}^{6}$. O Rede de Saberes/NEPPI ficou responsável por toda a organização do curso de extensão e pelo cronograma.

A primeira etapa foi realizada em Campo Grande, na UCDB, e contou com alunos do Estado que cursam Direito na UCDB, UEMS, UNIGRAN e alguns formados. O conteúdo estudado foi Direito Constitucional, sempre voltado para a questão indígena, gerou grandes debates entre os acadêmicos o tema e o professor foi um advogado atuante nas causas indígenas no País, Paulo Machado Guimarães, atualmente advogado do CIMI. A primeira etapa intensiva foram três dias inteiros.

* Acadêmica Indígena Kadiwéu, do curso de Direito da UCDB (MS) carla8803@hotmail.com 
A segunda, também realizada em Campo Grande, foram três dias de muitos debates, percebi que todos têm muito interesse em aprender, os acadêmicos de outras instituições de ensino superior também sempre presentes no curso ministrado por Rosane Lacerda, ex-advogada do CIMI e grande advogada da causa indígena. O conteúdo tratou de noções sobre propriedades imateriais, ou seja, bens patrimoniais indígenas e da nova Declaração dos Povos Indígenas.

Antes de serem realizadas as etapas intensivas foram feitos, durante um dia, geralmente são no final de semana, debates de temas referentes a questões indígenas, por um professor ou advogado que trabalha com a causa, para se falar sempre da questão indígena. É preciso ter conhecimento na prática de como funcionam realmente os órgãos competentes da Justiça. Essas etapas foram realizadas onde tem maior número de acadêmicos indígenas do Estado de Mato Grosso do Sul, ou seja, UCDB E UEMS. Nós, da UCDB, tivemos oportunidade de conversarmos com o Rogério Batalha, do CIMI de Mato Grosso do Sul, e o grupo da UEMS teve um encontro com Wilson Matos, um advogado Terena que atua em Dourados.

A terceira etapa foi realizada em Dourados, cidade onde se encontra a maior parte dos acadêmicos de Direito do Estado pela Universidade Estadual. O tema tratado nesta etapa foi Direito Penal e quem ministrou foi a atual advogada do CIMI de São Paulo, Dra. Michael Nolan.

É de suma importância o curso de extensão aos acadêmicos indígenas de Direito, trouxe uma outra visão do Direito aprendido em sala de aula, mostra que realmente existem muitos direitos inerentes aos povos indígenas, mas que são totalmente desconhecidos por todos que atuam nos órgãos competentes, são ignorados pelos docentes que ministram aula no dia-a-dia aos acadêmicos índios. Realmente o curso tem como finalidade capacitar os acadêmicos para atuar futuramente nas demandas indígenas. Ainda mais em um Estado como Mato Grosso do Sul, totalmente anti-indígena, surge a importância de se ter indígena habilitado para atuar em respectivas áreas, onde diariamente surgem conflitos envolvendo índios em retomadas de terras, muitas vezes vistos como invasores de terras e outras imagens pejorativas que circulam diariamente nos jornais do Estado. Os indígenas formandos não vencem a demanda devido ao grande número, são diversos os casos enfrentados por eles.

O curso tem duração de um ano e meio com cronograma específico da questão Indígena, suas legislações, os problemas enfrentados diariamente pelas comunidades dos acadêmicos são alguns dos diversos temas 
abordados durante os encontros. O curso é uma experiência inédita no país que teve essa finalidade. Em nenhuma universidade havia um curso específico para acadêmicos indígenas com suas respectivas demandas enfrentadas por eles e suas comunidades e legislação pertinente ao tema indígena.

Atualmente este curso vem clarear as dúvidas dos acadêmicos pertinentes aos conflitos e as demandas enfrentadas por todos em suas aldeias quanto à legislação indígena.

Devido a alguns contratempos houve atraso para realização do término do curso,1 então irá até 2009. Provavelmente, este curso será um marco muito grande na história dos povos indígenas do Estado, pois nele não apenas relata como "caminhar perante os órgãos competentes, mas também, como aprender a fazer o Estado a respeitar nossos direitos", ou seja, nos mostra como devemos fazer valer nossos direitos, perante o Estado, que muitas vezes, ignora as populações indígenas do país.

Após o término do curso pretendemos continuar nos articulando para ocupar nossos espaços a fim de que possamos cada vez mais ajudar as nossas populações indígenas em geral, pois elas se encontram em uma carência muito grande, não só por falta de auxílio nas demandas de Direitos, mas nas áreas de saúde, educação e outros problemas, também, relativos à questão indígena.

O curso de extensão representa uma visibilidade para as outras pessoas, como discentes não indígenas, que os indígenas acadêmicos estão empenhados em ter uma qualificação excelente. Portanto, este curso visa o ensinamento não aprendido em sala de aula aos acadêmicos indígenas do Estado, fazendo com que futuramente possam atuar nas respectivas demandas dos povos indígenas do Estado. Ou seja, um preparatório aos acadêmicos para fazer valer seus direitos garantidos constitucionalmente, que atualmente são violados diariamente, por pessoas que não gostam dos índios, acabam cometendo violações cruéis à causa indígena, às pessoas dos índios e suas respectivas comunidades.

A seguir os temas do curso:

\section{"Direito indigenista para acadêmicos indios de MS"}

1. O ordenamento constitucional, legal e regulamentar brasileiro em relação aos povos indígenas. Distribuição de competências e atribuições constitucionais 
2. Direito Internacional sobre os Povos Indígenas - A relevância da Convenção 169 da OIT e dos Projetos de Declaração Universal e Interamericana dos Direitos dos Povos Indígenas.

3. A situação jurídica dos cidadãos indígenas.

- Denominação e registro.

- Direitos políticos.

- Perspectivas de atuação da administração pública federal em razão do fim da limitação da capacidade civil dos índios e conseqüentemente da tutela.

- Natureza jurídica das comunidades indígenas - Resolução n. 1, de 28 de dezembro de 2005, da Concla/FIBGE/MPOG.

- Direitos trabalhistas e previdenciários.

- Índios residentes em centros urbanos.

- Direito de organização associativa dos povos e das comunidades indígenas e legitimidade processual - art. 232 da CF.

- Reações a manifestações de preconceito e racismo.

4. Bens patrimoniais indígenas.

Direito autoral e de imagem.

Direito intelectual.

5. A noção sobre Direitos Originários sobre as terras que os povos indígenas tradicionalmente ocupam.

Direitos à posse permanente e ao usufruto exclusivo (decisão do TCU) e atividades econômico-produtivas pelos povos indígenas.

Inalienabilidade, indisponibilidade e imprescritibilidade. Superposição de Unidades de Conservação em Terras indígenas. Terras Indígenas e Faixa de Fronteira.

6. Elementos constitutivos da Terra tradicionalmente ocupada por povos indígenas.

- A relevância dos usos, costumes e tradições na definição do que é terra tradicionalmente ocupada por índios.

- Crítica à "teoria dos círculos concêntricos" e questões suscitadas no Memorial da Aracruz Celulose no Procedimento administrativo de demarcação da terra Tupinikim, elaborados por Nelson Jobim.

- Súmula 650 do STF.

- Disputas possessórias. 
7. O Procedimento administrativo para demarcação de terras indígenas Natureza jurídica da demarcação das terras indígenas.

Fases procedimentais: identificação; contraditório; delimitação; demarcação; homologação; registros (CRI e no SPU).

Teses sobre a demarcação e a homologação das demarcações das terras indígenas:

- Questionamentos sobre a constitucionalidade do Dec. 1775/96.

- Aplicação da Lei sobre Processo Administrativo.

- PLS 188/2004 e outras PECs e proposições legislativas.

- Aprovação do Congresso Nacional ou do Senado Federal para a homologação das demarcações das terras indígenas pelo Presidente da República - (PECs).

- Manifestação prévia do CDN sobre a homologação das demarcações das terras indígenas - MS 25483/STF.

Questionamentos administrativos e judiciais contra os procedimentos administrativos destinados à demarcação das terras indígenas.

8. Hipóteses constitucionais de restrições aos direitos indígenas sobre as terras que tradicionalmente ocupam.

- Obras e projetos desenvolvimentistas incidentes em Terras Indígenas - rodovias (o caso Morro dos Cavalos), hidrovias, ferrovias, linhas de transmissão de energia elétrica.

- Construção de Usinas Hidrelétricas - aproveitamento de recursos hídricos (Agravo de Instrumento sobre UHE Belo Monte, no TRF 1 a Região, Desemb. Fed. Selene Maria de Almeida).

- Pesquisa e lavra de minérios em terras indígenas.

- Remoção temporária de comunidades indígenas de suas terras.

9. Organização, estrutura e funcionamento dos órgãos da administração pública que atuam com povos indígenas: Funai, Ibama, Incra, Funasa, Ministérios, CNPI, AGU e conselhos e comissões com a participação indígena.

Responsabilidades do Poder Público e o exercício do Poder de Polícia da União em Terras Indígenas:

- A atuação das Forças Armadas e da Polícia Federal e a inconstitucionalidade parcial do Dec. 4.412/2002.

- Aplicação do Estatuto das Cidades e a questão indígena.

10. Atenção integral à Saúde Indígena.

- O subsistema de atendimento à saúde indígena. 
- Responsabilidades das Unidades da Federação.

- Constitucionalidade dos convênios com organizações indígenas e com entidades e instituições de ensino e pesquisa.

11. Educação Escolar Indígena.

O papel do MEC, do CNE, das Secretarias Estaduais de Educação e dos Municípios.

12. Competência da Justiça Federal para processar e julgar crimes envolvendo índios - Crítica à Sumula 140 do STJ - RE n. 419.528-3/ STF e HC 65898/STJ.

13. Função institucional do Ministério Público Federal - a atuação da $6^{\underline{a}}$ Câmara de Coordenação e Revisão dos Direitos e Interesses dos Povos Indígenas da Procuradoria Geral da República.

14. Crimes envolvendo índios - instituto da detração penal - Casos Neguinho Truká e Joel Brás Pataxó, ambos no STJ.

15. Mudança da legislação indigenista:

Recuperação histórica da tramitação dos projetos de lei que pretendem alterar a legislação indigenista e a movimentação das forças políticas no Congresso Nacional.Temas tratados nos projetos de lei que visam dispor sobre a nova legislação indigenista:

- Princípios.

- Definições: Povos, Sociedades, ou Comunidades indígenas.

- Registros.

- Patrimônio Indígena: conhecimento tradicional, propriedade intelectual, direitos autorais e patenteamento.

- Usufruto Exclusivo.

- Relação com particulares: fim da tutela, atos e negócios entre índios e não-índios.

- Responsabilidades do Poder Público: Poder de Polícia, Infrações Administrativas, proteção policial, competência da Justiça Federal e da Justiça comum em casos criminais.

- Terras indígenas: demarcação das terras indígenas.

- Exploração Mineral: inversão do que o texto constitucional determina.

- Aproveitamento de Recursos Hídricos.

- Utilização de potenciais de energia hidráulica.

- Assistência Especial: Saúde, Educação escolar, atividades produtivas. 
- Normas Penais e Crimes.

- Disposições finais e transitórias.

\section{Notas}

${ }^{1}$ O Programa Rede de Saberes tem como objetivo acesso e permanência dos acadêmicos indígenas na universidade. É patrocinado pela Fundação Ford. Atualmente o projeto envolve quatro Universidades: Universidade Católica Dom Bosco, Universidade Estadual de Mato Grosso do Sul, Universidade da Grande Dourados e Universidade Federal de Mato Grosso do Sul/Campus de Aquidauana.

${ }^{2}$ Ordem dos Advogados do Brasil.

${ }^{3}$ Núcleo de Prática Jurídica do Curso de Direito - UCDB.

${ }^{4}$ Universidade Estadual de Mato Grosso do Sul.

${ }^{5}$ Núcleo de Estudos e Pesquisas das Populações Indígenas - UCDB.

${ }^{6}$ Conselho Indigenista Missionário.

Recebido em 20 de agosto de 2008.

Aprovado para publicação em 28 de agosto de 2008. 
